\title{
How effective are Community-Based Primary HealthCare Interventions on Infant and Child Survival?
}

\author{
Article by ${ }^{1}$ Sukerazu Ahmad Alhassan, $\&{ }^{2}$ Robert Kuganab-Lem (PhD) \\ ${ }^{1}$ Community Health Nurses Training College \\ Tamale, Ghana. \\ Email:sukera2000@yahoo.com/sukera2000@texilaconnect.com \\ ${ }^{2}$ Dean and Public Health Services Consultant \\ School of Allied Health \\ University for Development Studies, \\ Tamale, Ghana \\ Email: kugarobert@hotmail.com
}

\begin{abstract}
Introduction. Child survival remains one of the most important public health challenges in Ghana. The promotion of community-based child health interventions is among the key strategies to improve child survival. The primary goal of the study was therefore to assess the potential of community-based primary health care interventions on child survival in Yendi Municipality. Method. The study was a community-based cross sectional study. The study employed multi-stage random cluster sampling procedure to select households and villages in Yendi district. Both quantitative and qualitative methods were used to collect data from the study target population which included the caregivers, the community based agent and community health officers. Results. The study established high level of caregivers' knowledge on prevention of diarrhea, and malaria. It revealed similarities in some knowledge and practice and showed significant difference in some home based care of children. It also noted significant association between caregivers' health seeking behavior and presence or availability of health facility. Conclusion. The finding concluded that there was general improvement in the health and survival of children less than five years of age. This was however, better in communities with health facility. Hence community-based primary health care have a positive effects on child survival.
\end{abstract}

\subsection{Introduction}

The 1978 Global Health Conference goal of achieving "health for all" by the year 2000 was endorsed by all African governments (WHO and UNICEF, 1978). Yet, as the new millennium approached, accessible health care remained a distant dream for most African households (Bryce, 2003). The Millennium Declaration, adopted at the UN Millennium Summit in New York in 2000 by the world leaders, set new targets to improve child survival (United Nations, 2000). With only few days remaining to meet the United Nations Millennium Development Goal four (MDG4) of reducing childhood mortality by two thirds by 2015 , no African country is on target (Phillips, 2006). Therefore, Ghana is not also on track to achieve the MDG4.

Mortality of children under the age of five remains one of the most important public health challenges in developing countries. Approximately, 10.5 million children aged less than five years die each year in less-developed countries, despite remarkable progress that has been made globally in reducing child deaths during the past 50 years (Perry, et al, 2007a; Black, et al, 2003). In Sub-Sahara Africa, an estimated $80 \%$ of acute febrile illness and death in infants and children under the age of five occur with little or no contact between household caregivers and professional health providers (Breman, et al. 2001). This is due to poor access to health services, insufficient resources at household level, poor knowledge and practices among caregivers and inadequate health facilities (Schellenberg, et al 2003). Globally, the number of children dying annually before age five has declined from 18.9 million in 1960 to 
South American Journal of Public Health

Special Edition May 2016

9.2 million at present despite the fact that the annual number of births has increased from 96 million in 1960 to 135 million in 2007 (Ahmad et al., 2000; Black et al., 2003; UNICEF, 2008a). Furthermore, the dramatic global disparities in the health status of children are increasing rather than declining.

In Ghana under-five mortality is 80 deaths per 1,000 live births in the most recent five-year period. This means one in every thirteen Ghanaian children dies before the fifth birthday. Infant mortality is 50 deaths per 1,000 live births and child mortality is 31 deaths per 1,000 children age one year. Neonatal mortality is 30 deaths per 1,000 live births in the most recent five year period, while the risk of post-neonatal mortality is 21 deaths per 1,000 live births. Neonatal deaths account for 60 percent of the deaths in infancy (Ghana Statistical Service \& Ghana Health Service, 2008; 2009).

Results from six Ghana Demographic and Health Survey (GDHS)conducted in 1988, 1993, 1998, 2003, 2008 and 2014 indicate under- five mortality trends of 155, 119, 108, 111, 80 and 60 deaths per 1,000 live births respectively. The trend shows that Ghana has achieved a reduction in the child mortality rate, although the levels still remain high. It is now clear that the 2015 target of reducing the child mortality rates to two-thirds (40 per 1000 live births)will not be met unless coverage of effective child survival interventions is increased (Daily Graphic, 2012).

Yendi Municipal in 2009 recorded 26 neonatal deaths of which $40 \%$ is as a result of fever, convulsion $20 \%$, and $40 \%$ other causes. In 2010, 21 neonatal deaths were also registered, $70 \%$ caused by fever, $10 \%$ convulsion, and $20 \%$ others causes. 2011 saw increased cases of neonatal deaths of 32 . Fever contributing $60 \%, 20 \%$ convulsion, $20 \%$ others causes (Yendi District Health Management Team, 2012).

It is expected that community-based comprehensive primary healthcare interventions should improve infant and child health. Perry and Freeman (2009) defined Community based Primary Healthcare (CBPHC) as a process through which health programs and communities work together to improve health and control disease. It also includes the promotion of health behaviors at the household level as well as the provision of health care and health services outside of static facilities at the community level. Perry and Freeman (2009) noted further that Community-based Primary Healthcare (CBPHC) includes the following three different types of activities: Communications with individuals, families and communities to improve health practices; Social mobilization and community involvement for planning, delivering and using health services; Provision of health care in the community, including preventive services (e.g., immunizations) or curative services (e.g., community-based treatment of malaria, diarrhoea and pneumonia). Therefore, child survival intervention that emphasize immunizations, prevention and treatment of acute respiratory infection and diarrhoea, growth monitoring, and appropriate infant feeding continue to be recommended strategies for child survival (Perry, et al, 2009a; Perry, et al, 2009b).

According to WHO (2006), the child health goal is measured by, under five mortality, infant mortality rate, and the proportion of one year-old children immunization against measles. Research has also shown that high coverage of effective interventions such as immunisation, exclusive breastfeeding for the first six months, growth promotion, nutrition rehabilitation, use of insecticide treated net and vitamin A supplementation have the potential to reduce child morbidity and mortality (Darmstadt et al, 2005). It is estimated that immunizations can prevent three million child deaths a year.

However, the utilization of the various interventions has not led to the desired levels of child survival in Ghana. These interventions needed to achieve the millennium development goal of improving child survival are available, but are not being delivered to the mothers and children who need them (Jones, et al, 2003). This suggests that the interventions to improve child survival exist but the children continue to die because the interventions are not reaching them. Also according to the World Health Organization, many sick children who are brought to the attention of health providers do not receive adequate assessment and treatment. 
There is growing recognition that child survival intervention which reach beyond the walls of health care facilities and which involve the community as partners have a great potential for further increasing child survival. However, the role of the community as a partner in these child survival interventions has been given much less attention. There is also evidence from many countries that the concept community-based interventions can be highly effective in improving the health of populations, especially when these interventions are connected to other community-based activities for social and economic improvement. (American Public Health Association, 2009).

A number of these community-based interventions and programs had been implemented in Yendi municipality and this study sough to evaluate its effects on child survival. Yendi municipal health directorate for the past years has been working to address the problems of child health and improve child survival. The directorate has achieved over $70 \%$ child immunization coverage, child access and utilization of Insecticide Treated Nets (ITN) of $80.8 \%$ and $64.3 \%$ respectively (Yendi District Health Management Team, 2010). It is one of the areas in northern region which is working hard to ensure every child survives. 7 However, the effort of the health directorate has met some difficulties. Despite the high coverage of some of the community based primary health interventions, there are still many children who do not benefit from the protection that community based primary health interventions provide. Majority of the child deaths that still occur in Yendi are caused by readily preventable or treatable conditions

Again, the directorate rarely conducts rigorous independent evaluations of the effects of the interventions. There is therefore, limited documentation and information in terms of research in community based primary health interventions on infant and child survival in Yendi municipality. Although such child survival interventions are usually carried out, their effectiveness is rarely researched into, and researchers usually focus on process and coverage indicators rather than its effects on child survival. Additional well-conducted research on the effects of community based primary health care on child survival efforts is needed. The study is therefore to examine the effects of community-based comprehensive primary healthcare programme on infant and child survival in Yendi Municipality.

\subsection{Method}

\subsection{Study design}

A research design is an organized collection of procedures used by researchers to collect data. It is used to structure the research and show how the major parts of the research project, samples, measures and methods work together to address the research question. Research design focuses upon turning a research question and objectives into a research project (Saunders et al, 2007).

In the consideration of the population at hand, a community-based cross sectional descriptive and comparative study was believed to be the most appropriate design for this study. According to Varkevisser et al, (2003)cross-sectional survey is aimed at quantifying the distribution of certain variables in a study population at one point in time that may cover physical characteristics, socioeconomic characteristics, behavior, knowledge, attitudes, beliefs, and opinions of the people.

Descriptive study involves the systematic collection and presentation of data to give a clear picture of a particular situation (Varkevisser et al, 2003). The objective of descriptive research is to portray an accurate profile of persons, events or situations (Robson, 2002). It deals with interpretation of the relationship among variables and describing this relationship. In this study, descriptive study was used to describe the effect that community-based comprehensive primary health has on infant and child survival. Whiles comparative study on the other hand was employed to compare communities with health facilities to those without health facilities.

Qualitative and quantitative information regarding child health activities in the communities was collected among caregivers at the household level, the CBVs/CBA at the community level and the CHOs at the facility level. 
South American Journal of Public Health

Special Edition May 2016

The rationale for the adaptation of this design is not farfetched: it observes, describes, and documents aspect of a situation as it naturally occurs. Hence for a researcher to get a true picture of the effect of community-based comprehensive primary health care on infant and child survival there is the need to assess the situation in it naturally occurring state through observation, description and documentation without manipulation of any variable whatsoever. Some authors note that the use of descriptive study design will easily permit replication of the study by others.

As noted the design has a number of strengths and weaknesses. A strength being that it helps summarize large amounts of data in a sensible way using a single indicator as well as predicts phenomena without manipulating factors that influence the phenomena. It also describes events as they naturally occur. Notwithstanding these strengths, the design also has limitations. One of these being that it is not useful in describing cause - and - effect relationship.

\subsection{Study population}

A population is the total collection of elements about which we wish to make some inferences (Cooper and Schindler, 2001). Anaman (2003) describe population in the context of research as elements, objects or events of a group that conform to specific criteria that the researcher intends to investigate to make generalizations. Kumekpor (2002) defines population in the context of research as the total number of all units/elements of the phenomenon to be investigated that exists in the area of investigation. In this study, the researcher's target population included the caregivers at the household level, the community health officers (CHOs), the community Based volunteers or agent (CBA) as well as reviewing community based surveillance registers and child health record booklets.

\subsection{Sampling method}

Sampling refers to the process of selecting a portion of the population to represent the entire population or the process of selecting a number of study units from a defined study population (Varkevisser, et al, 2003). Sampling is used because of limited time and resources available. The main purpose of sampling is to get a representation of the population to draw conclusions which are valid for the whole study population. The sampling technique that was used in order to get the accessible population and households was a community-based multistage, random cluster sampling procedure of households and villages in the Yendi district. Multi-stage sampling is a technique whereby the elements are successively selected randomly from natural occurring groups or areas and then selecting individual elements from the chosen groups and areas.

The district is composed of six (6)sub-districts and each sub-district has several villages. The following four-stage sampling procedure was adopted:

I. Four (4)Sub-districts was selected out of the six (6)sub-districts by simple random sampling.

II. For each Sub-district four (4) communities were selected by simple random sampling ( 4 × 4= 16 communities in total).

III. For each community selected 25 households were identified $(25 \times 16=400$ household in total). Since simply choosing households in the centre of the village would produce a biased sample, the following sampling procedure was carried out:

IV. The selection of households for interview was done by going to the centre of the village. A direction was randomly chosen. A bottle was spun on the ground and the direction of the bottleneck indicated the direction along which the houses were numbered.

The first house was selected randomly. Subsequent houses were selected by walking in the chosen direction and selecting every second house until the $25^{\text {th }}$ house was gotten. If the boundary of the community was reached and the interviewer still does not have 25 households, the interviewer returns to the centre of the community, walked in the opposite 
direction and continue to select the sample in the same way until the 25 households was obtained. In each house, women who had children less than five years were identified and only one was selected randomly for interview. If a house did not have an eligible respondent, the interviewer moved to the next house until the required number of respondents was obtained. In each community 25 respondents were interviewed. This was therefore produced a total of 400 respondents. However, there was a number of missing observations in some of the questionnaire items. Therefore only valid observations were used in the calculations and analysis.

In selecting individual survey subjects, the research assistants explained the nature of the study to an adult in each selected household, and inquired if there was/were one or more children aged five years or less who presently lived in the house. If there was, and a person who provided household health management to the child was available, that person was invited to participate in answering the questionnaire. If primary caretaker was not immediately available or no one at home, the house would be visited another time to conduct the interview. And if primary caregiver had more than one child aged less than five years, only one of them was randomly selected for the study.

\subsection{Sample size}

In research determining the appropriate sample size is very critical. The sample frame for this study considered the 8,336 households registered in the district (2010 population projection). The Sample size calculation was based on the assumption that approximately $50 \%$ of households have benefited from a community based primary health intervention. Calculations were made to allow a precision of $5 \%$, with an alpha type one error of $5 \%$; which resulted in minimum sample size households of 400 surveyed. Sampling of CHOs and CBA was determined by their availability during the visit to each of the selected villages.

Sample size calculation of households

$$
n=\frac{N}{1+N(e)^{2}}
$$

Where, $n=$ sample size

$N=$ total household population

$e=$ level of precision

$$
\begin{aligned}
& n=\frac{8336}{1+8336(.05)^{2}} \\
& n=381.68 \\
& n \approx 400
\end{aligned}
$$

\subsection{Data collection and study instruments}

Data collection for the study took place between April 2014 and December 2014. A questionnaire for caregivers of children under five years of age was designed. It was composed of four main sections:

1) Socio-demographic and household information of the child caregiver;

2) Knowledge and practices of household members concerning home-management of the sick infants and children under the age of five;

3) Health seeking behavior;

4) Child nutrition, immunization and other health risk factors.

The questions used a combination of multiple-choice and open-ended response formats. The open-ended questions provided an opportunity for respondents to elaborate and provide further details while the multiple-choice questions gave respondents time to provide appropriate answers to the questions by choosing from possible options made available. The multiple-choice questions were meant to minimize the rate of some respondents' failure to provide answers to questions due to time constraint. The tool was pre-tested. An individual 
interview guide was designed to collect information from CHOs and CBVs. It was designed with the assistance of a supervisor. The rationale for the selection of questionnaire over the other instruments is that, the interviewers can read and write. It also offered respondents enough opportunity to consult and verify in order to provide the right information.

\subsection{Analysis and presentation of results}

The end result of the data collection is the accumulation of raw data, in a quantitative form; such data are then summarized and subjected to statistical analysis. Standard scoring procedure was adopted and data was coded and analyzed statistically by using the SPSS (Statistical Package for Social Sciences)software. For the quantitative data the researcher categorized and analyzed it manually, and then used Percentages and frequencies to transform raw data collected from the field into more meaningful information which can easily understood by readers. The researcher also applied statistical tests like chi-square $\left(X^{2}\right)$, crosstabulations, one way ANOVA and regression analysis to measure the degree of relationship and difference of the data collected.

Chi-square analysis in statistics is to test the goodness of fit to verify the distribution of observed data with assumed theoretical distribution. It is a statistical measure used in the context of sampling analysis for comparing observed variance to theoretical variance. In this study, it was used to compare knowledge and practice factors of communities with health facilities to communities without health facilities. Again it was employed to test for the association of health seeking behavior among communities with health facilities and the community without health facilities.

Analysis of variance (ANOVA)is an extremely useful technique concerning research. This is used when multi sample are involved. It is used to test the difference among different groups of data for homogeneity. If we take only one factor and investigate the differences amongst its various categories having numerous possible values one-way ANOVA can be used. Therefore One-way ANOVA was used in the study to test for homogeneity among accessibility factors such as time taking or distance to the nearest health facility and health seeking behaviors of the different samples in each cluster of the study.

The Regression analysis deals with the nature of association between two or more variables. In regression analysis we are concerned with the estimation of one variable for a given value of another variable on the basis of an average mathematical relationship between the two variables. Hence the analysis was used to find out whether improvement in community based services such as outreach and household services predict improvement in child survival.

\subsection{Quality control}

In order to obtain information on the acceptability and quality of the intervention, caregivers of children under five years of age were interviewed in their households so that they can feel comfortable to provide accurate and complete answers to maintain quality of the study.

The survey team was made up of interviewers who were health staff from the district. They all have experience in field surveys and speak the various dialects present in the district. Data was therefore collected from the respondents in their native language. Therefore, questions were asked to the best of their understanding and no ambiguities, so quality was not compromised. In addition, the supervisor who coordinated the data collection was also a health staff and was available to make sure that omissions and mistakes were rectified. Before and during data processing, the information was checked for completeness and internal consistency.

\subsection{Ethical consideration}

Written ethical clearance and authorization were sought from the Regional Director of Health Services (RDHS) for Northern Region through the District Director of Health Services 
(DDHS) for Yendi and was given. For interviewees, verbal consent was sought from each individual before the interviews conducted. Confidentiality was assured and ensured.

\subsection{Study limitations}

The study had limitation as with most studies. The first limitation was the sample size as a result of the time constrain for such extensive study. The target population of the study was all the primary caregivers of children less than five years, CBAs and CHOs in the municipality. However, complete coverage of those populations was not possible considering the time, the nature of the study and size of the municipality. This in fact limited the generalization of the result. Secondly, self reporting may be subjected to reporting errors and biases, and could not be easily addressed. Finally the scope of the study was limited to only community level interventions which agreeably cannot by themselves alone increase child survival without facility level interventions.

\subsection{Reliability and validity}

Reliability refers to the extent to which data collection techniques or analysis procedures will yield consistent findings. Easterby-Smith et al., (2002)explains that reliability can be assessed by checking whether the measure will yield the same result on other occasions, whether similar observations be reached by other observers, and the transparency in how sense was made from the raw data. Robson (2002)assets that subject or participant error, subject or participant bias, observer error and observer bias may be threats to reliability. Hence, data collection was carefully planned to eliminate possible sources of bias during data collection. This was done by using mostly closed- ended questions and where open-ended questions where used guidelines on how to ask the questions was provided. The questionnaire was also standardized and was not vaguely phrased. Pre-testing was done to identify any possible problems and to ensure that the tool for data collection was easily understood and completed. The pre-test results identified errors in some of the questions and were corrected. Both interviewers and respondents find some question difficult to understand and these were also re-phrased.

Validity is concerned with whether the findings are really about what they appear to be about. Validity ensures the ability of a scale to measure the intended concept. The questionnaire was structured taken into consideration the main and the sub-objective of the study, so that the outcome provided answers to the research questions and met the research objectives. The questionnaire was place in a logical order and also free from ambiguity. The interviewers were trained so that deviation from the sampling procedure set out in the proposal was avoided. All these measures were put in place to reduced variability, thereby ensuring reliability and validity.

\subsection{Results and analysis}

\subsection{Socio demographics of respondents}

Table 1.0 presents the socio-demographic characteristics of caregivers of children under five years of aged who were responded to the questionnaire for this study. Majority of the women caregivers $(36.1 \%)$ were between 26-30 years, the youngest age group (14-19 years)was $2.6 \%$ and the oldest age group (36-40 years)was $11.0 \%$. Only $0.8 \%$ said they do not know their age. In addition, there were more married women $(96.2 \%)$ than singles $(2.5 \%)$. Only $0.5 \%$ and $0.8 \%$ were separated and divorced respectively. On the relationship of the respondents to the household head, $96.5 \%$ were their husbands, $8.3 \%$ non-related and the remaining were other relatives. The distribution of ethnicity showed mole Dagbomba as the majority representing $54 \%$, Konkomba $44.8 \%$ and Gonja $0.2 \%$ of the household surveyed. Muslims form the majority (63.9\%)of the respondents. Christians were 14.3\%, Traditionalist $18.3 \%$, No religion $3.5 \%$ and other $1 \%$. For educational attainment, the women caregivers had low educational levels, most of the mothers $(85.5 \%)$ had no formal education whiles $9.3 \%, 4.1 \%, 0.8 \%$ and $0.3 \%$ had primary, junior high, senior high and tertiary respectively. 
South American Journal of Public Health

Special Edition May 2016

\subsection{Knowledge on preventive measures of specific illnesses}

The study assessed the Knowledge of the respondents on preventive measures of specific illnesses. The findings are summed up in the Table 2.0.

Table 2.0 indicates that $62.3 \%$ strongly agreed and $36.2 \%$ agreed that hand washing before feeding child can prevent diarrhea, whiles the remaining $1.6 \%$ have the opposing view to washing child's hands before the child feeds can prevent diarrhea. In general, 92\% of the respondents were of the view that washing child's hand after toilet can prevent diarrhea, whereas $8 \%$ of the respondents disagreed to the statement as a preventive measure of diarrhea. Majority of the respondents (54.5\%)have strongly agreed with the statement that cutting child's finger nail can prevent diarrhea, $41 \%$ agree whiles $4.5 \%$ disagreed to keeping child's finger nails short have the possibility of preventing diarrhea.

For breastfeeding and diarrhea prevention, $86.8 \%$ agreed to practicing exclusive breastfeeding for children below six months prevent them from diarrhea whiles $13.2 \%$ were not in agreement to exclusive breastfeeding of less than six month babies preventing them from diarrhea. A look at the data reveals that $86.8 \%$ of the respondents have given credence to the fact that using cups, plates and spoons instead of feeding bottles prevent diarrhea and $13.2 \%$ disagreed to the statement.

Table 2.0, further illustrates that $54.4 \%$ were of the strong view that washing fruits or vegetables thoroughly before the child eats prevent diarrhea, $44.1 \%$ agreed to the notion that washing fruits or vegetables thoroughly before the child eats prevent diarrhea and only $1.5 \%$ held the contra view that washing fruits or vegetables thoroughly before the child eats will not prevent diarrhea. The illustration shows that $59.3 \%$ strongly agreed to the fact that given the child clean water prevent diarrhea, $38.4 \%$ agreed to the notion whiles in all, $2.3 \%$ disagreed.

It was also indicated that $62.26 \%$ strongly agreed, $37 \%$ only agreed, and $1.8 \%$ disagreed to the statement of giving the child well cooked food will prevent diarrhea in children. It also reveals that $56.7 \%$ strongly agreed and $39.5 \%$ agreed to the statement that heating food when cold before given to child can prevent diarrhea whereas 3.3\% strongly disagreed and $0.5 \%$ only disagreed. The table also shows majority of the respondents $(59.4 \%)$ strongly agreed and $38.6 \%$ agreed to the notion that covering prepared food to keep flies away prevents diarrhea whereas only $2 \%$ disagreed to covering the child's prepared food to keep flies away will prevent the child of getting diarrhea.

According to illustration, the respondents representing $48.7 \%$ agreed strongly and 34.4 have only agreed, whiles $15.6 \%$ have disagreed strongly and $1.3 \%$ only disagreed to the idea of covering dustbins and proper disposal of refuse will help prevent diarrhea. The likelihood of child's toileting training preventing diarrhea showed majority of the respondents accepting whiles $15.9 \%$ disagreed to the statement that 'training children to use the chamber pot as early as possible and dispose of the waste immediately and properly' is a measure to prevent diarrhea. Finally it was demonstrated that, $99 \%$ of the respondents in sum have agreed that giving ORS to children prevents diarrhea.

Table 2.0 again shows the perception of respondents on malaria prevention with most of the respondent (62.4\%)strongly agreed, 31.8 agreed, whiles 5.5\% strongly disagreed and only $0.3 \%$ disagreed to child sleeping under insecticide treated bed net as a measure for preventing malaria. Preventing mosquito breeding was perceived to prevent malaria. In all $97.7 \%$ of the respondents were of the view that weeding the surrounding of homes prevents breeding of mosquitoes and $2.3 \%$ do not believed that weeding the surrounding of homes prevents breeding of mosquitoes thereby preventing children from getting malaria. $92.5 \%$ of the respondents were of the view that draining stagnant/ pool of water to prevent the breeding of mosquitoes will also prevent children from malaria whereas $7.5 \%$ disagreed to the statement of draining stagnant water as a way to prevent malaria. $97 \%$ in sum agreed to the notion, whereas 3\% have disagreed to the fact that covering water containers in the house always to prevent the breeding of mosquitoes is likely to also prevents malaria. The study also reveals that screening doors and windows prevents mosquito bites and hence a measure to prevent the children from malaria. 


\subsection{Knowledge of care givers on management and practice of childhood illness}

The researcher studied the knowledge on management and practice of care givers and made comparison to ascertain from the study whether there was significant difference in knowledge o management and practice between communities with health facility and communities without health facility. This was done by comparing knowledge on management and practice factors of communities with health facilities to communities without health facilities. The results were as follows.

Table 3.0 summarizes the health knowledge and practice of caregivers. Knowledge and practice of household management of some selected childhood illnesses was found to be high. Most caregivers (52.5\%) reported to have used ORS alone to treat children with diarrhea. About $39.9 \%$ of the respondents used ORS plus zinc to treat children suffering from diarrhea, $3 \%$ used traditional medicine (local plan preparations)and 1.5\% said they do nothing to stop diarrhea in children. As to whether respondents give more drink to child with diarrhea, almost all the caregivers (99.2\%)agreed that a child with diarrhea needs to take in more drink and fluids the remaining 0.8 have no knowledge.

Majority of the respondents who agreed to give more drink to children with diarrhea knew that they do so to replace loss fluid. Almost all the respondents know ORS, and can correctly describe oral rehydration salt (ORS). In addition, majority number (78.1) of respondents accepted that breast milk should be given to baby less than 6 months with diarrhea followed by ORS, and $72.8 \%$ of the respondents could described the preparation of ORS correctly. The remaining $26.2 \%$ were unable to describe the preparation of ORS correctly.

For those caregivers whose children have experienced fever, greater percentage $(51.5 \%)$ of the caregivers manage the fever to prevent convulsion by bathing children with lukewarm water and giving paracetamol to reduce temperature. Caregivers who only bath the child with lukewarm water were $39.1 \%$ and the remaining $6.6 \%$ managed the fever to prevent convulsion by dressing child lightly and cooled with damp cloth if child is sick with fever. Around $95 \%$ said they heard about malaria and $76.7 \%$ agreed strongly to the fact that people became infected with malaria from mosquito bite. For correct medicine to treat malaria, $56.4 \%$ indicated ACT plus paracetamol as the correct combinations of drugs for the treatment of child's malaria, and the number of days ACT is given to a child with malaria even if the child gets better, $86.1 \%$ knew that a child taking ACT for malaria should be treated for at least three days (i.e. Complete treatment). Again the caregivers demonstrated some level of correct knowledge of dosage for ACT (66. 2\%) and correct dosage for paracetamol (78.2\%).

Most of the caregiver (92\%)reported that they heard about pneumonia and majority of the respondent knew that fever, chest in-drawing, and fast breathing were signs of pneumonia and in sum, $85 \%$ agreed and $15 \%$ disagreed to the fact that antibiotics are treatment for pneumonia. For the question on sick child referral, $68.1 \%$ of caretakers stated that last episodes of severe diarrhea, malaria, or pneumonia suffered by their children that was reported to the CBA were referred by CBAs to health facility for proper care.

There were similarities in the respondents in the number of knowledge and practice factors such as; giving more drink to child with diarrhea, reasons for giving more drink, number who know ORS, number who can described ORS, number said to give breast milk followed by ORS to a baby less than 6 months with diarrhea, number heard about malaria, the agreement that people become infected with malaria from mosquito bite and number heard about pneumonia. They showed no statistically significant difference beyond $5 \%$ level when comparisons of these various components of knowledge and practice was made between communities with health facility and those without.

Also, the results showed statistically significant difference in the use of drugs to treat diarrhea, number who can prepared ORS, management of child to prevent convulsion, correct medicine to treat malaria, number of days ACT is given to a child with malaria, knowledge on signs of pneumonia, referral to health facility and correct knowledge of dosage of ACT and paracetamol. The $\mathrm{p}$ values are clearly showed in table 3.0. 
South American Journal of Public Health

Special Edition May 2016

Table 3.0 also reveals that there was high knowledge and practice among those with health facility than those without health facility. For example, $54.3 \%$ of those in communities with health facility stated correctly the management of child with convulsion at home as against $27.3 \%$ in communities without health facility.

\subsection{Health seeking behaviour}

There researcher studied the health seeking behavior of the respondents. The researcher again determined whether there exit an association between caregivers health seeking behavior and presence of health facility. The reason behind this was to ascertain whether availability of community-based primary health care increase health seeking behavior. Table 4.0 is the summary of the results.

Table 4.0 shows results of treatment seeking behavior. Majority of the care givers sought help from CBA and husbands if child was ill, and some (1.8\%)seeks help from Traditional Healer. No person seeks help from friend. About half (51.8\%) reported to have bought medicine from CBA, and $22.4 \%$ bought from chemical seller for the treatment of their children. For medicine that are kept at home for the home management of under-five illness, $71 \%$ of the household surveyed possessed ORS, $75.3 \%$ have paracetamol at home and less than $50 \%$ of the surveyed households have ACT present in the household. Other drugs observed to be kept in the households were; Chloroquine (22.5\% of the households), Zinc (32.2\% households), Amoxycillin (37.7\% huseholds)and 39\% household have in their possession traditional medicine. There was also evident from study as shown in the table that presence of danger signs determines why families seek care for their sick children at the facility. Only $13.1 \%$ and $31.8 \%$ will seek care as a result of proximity to health facility and perceived competence of health staff or quality of service rendered respectively. Half of the respondents take less than 30 minutes to go from their homes or community to the nearest health facility and more than have (57.8\%)go by foot to the nearest health facility. Nobody go by vehicle.

The table shows that there was insignificant association between health seeking behavior and presence of health facility concerning keeping chloroquine and traditional medicine at home. In contrast, the result showed significant difference regarding keeping ORS, ACT, paracetamol, zinc and amoxicillin at home. It is noted from the table also that there was statistically significant association between caregivers health seeking behavior and presence of health facility concerning person from whom help is sought if child was ill, where medicine was bought, where caregivers first seek care for sick children, reason why families seek care for their sick children at health facility, the distance from home or community to the nearest health facility and the means of transportation to the health facility.

For the sake of better analysis, the study also assessed whether accessibility of community based primary health care increases health seeking behavior. The analysis was done using ANOVA to test for homogeneity among accessibility factors such as time taking or distance to the nearest health facility and health seeking behavior. The following result (Table 6.0)was generated. One-way ANOVA showed no significant difference among the means regarding person from whom help is sought if child was ill ( $\mathrm{F}(3)=1.62 ; \mathrm{p}>0.01)$. One-way ANOVA showed $\mathrm{F}$ to be significant beyond 0.01 level regarding where medicine was bought $(\mathrm{F}(3)=$ 5.03; $\mathrm{p}<0.01)$. The test statistics, $\mathrm{F}$ showed significant difference regarding ORS, ACT, paracetamol, zinc, Amoxycillin, and traditional medicine of the list of drugs that were kept at home by caregivers, but showed no association regarding chloroquine. However, there is a significant relationship beyond $1 \%$ level concerning where caregivers first seek care for sick children shown in table above: $\mathrm{F}(3)=8.4 ; \mathrm{p}<0.01$. The results also showed an association among the means beyond 5\% level regarding reason why families seek care for their sick children at health facility: $\mathrm{F}(3)=2.64 ; \mathrm{p}=0.050$. 


\subsection{Morbidity and mortality}

The studied tried to ascertain from the respondents the morbidity and mortality hence the child survival rate of the municipality. The findings are summed up in the figures 1,2 and 3. From the figure 1, fever (malaria)was found to be the most common illness suffered by the children of less than five years. Closely followed was diarrhea. ARI represents $11.8 \%$ and malnutrition representing $1.5 \%$ of child illness in the study area. Of those surveyed, $9.8 \%$ reported to have lost their children for that matter mortality within the last five years. The respondents who have not lost child within this same period were $90.2 \%$. This is illustrated in figure 2. Fever (malaria) and Diarrhea were found to be the major cause of death among children of less than five years. Fever (malaria)represents $44.7 \%$ of the cause of child deaths, another $44.7 \%$ cause of child deaths is due to diarrhea, the same as malaria. ARI (pneumonia)represents $2.9 \%$ and home accident also $2.9 \%$. The results are illustrated in figure 3.

The research further compared communities with health facility and those without health facility using cross-tabulation. This was to find out the effect of health facilities on child survival. The summary is presented in table 6.0. From Table 6.0, a cross tabulation of presence of health facility and number of child death within the last five years showed higher percentage $(12.9 \%)$ of death in communities without heath facility and lower percentage (7.6\%)of deaths in communities with health facility.

In order to get a wider perspective and better understanding, CBAs views were also sought using interview guide and the following revelations were made. The number of CBAs interviewed was 33. All the CBAs were in possession of $\mathrm{C}$ - IMCI kits and all the kits were stocked with adequate drugs to meet the community needs. According to the CBAs diarrhea was the most common illness suffered by children followed by malaria and then acute respiratory infections (ARI), but stated that malaria was the number one cause of death in under-fives children. The next cause of child death reported by the CBAs was diarrhea followed by ARI and malnutrition. This also conformed to the household survey findings above.

The review of the 33 CBAs registers revealed a total of 38 under - fives deaths within a year. According to the CBAs registers malaria again was found to be the major cause of deaths in under-fives followed by diarrhea and ARI (pneumonia). In all, 119 children aged six months to five years were reported to the CBAs for treatment within a month. $7.5 \%$ of those reported present danger signs. $81.5 \%$ were assessed to present fever (malaria), 51.2\% diarrhea, and $15 \%$ fast breathing (pneumonia). However, some of them resented more than one problem. $10 \%$ were referred to trained heath worker or provider. Most of the CBAs identified diarrhea by frequent passage of stools, watery stool for more than three times a day and with or without dehydration and sunken eyes. Majority of CBAs identified Pneumonia by fast breathing, others CBAs as child with chest in-drawing, cough, and difficulty breathing. Malaria was also identified by rise in body temperature and weakness. Knowledge was found to be high (93.9\%)in terms of drug treatment for diarrhea, ARI, and malaria. CBAs used ORS + Zinc for diarrhea treatment, amoxicillin for ARI and ACT + paracetamol for malaria.

Convulsion, blood in stools, child no Table to eat or breastfeed, severe dehydration and when the condition is not improving after taking appropriate drugs for three days were the indications of signs of severe illness. Sick children were said to be referred to the next level when they present persistent fever, convulsion and no improvement after taking ACT for treatment of malaria for three days. Majority of the CBAs assessed malnutrition by the used of MUAC tape and observation of weight loss. And if a child was assessed to be malnourished, all of the respondents agreed that the child was referred.

The researcher also sought the views of CHOs using interview guide. The following were the views expressed. Total number of CHOs interviewed was 25 and the types of facilities were mainly CHPS compounds and health centers. The maximum number of staff in the health facility was found to be seven and the CHPS compound was two. However majority of the CHPS compounds have only one $\mathrm{CHO}$ at post. All the health facilities were operated by 
South American Journal of Public Health

Special Edition May 2016

GHS. Category of health staff posted to the community-based facilities were found to be Medical assistants midwives, community health nurses field technicians and health assistants.

$86.6 \%$ of those interviewed indicated that, at least a trained health provider is always and at all times around to attend to sick children at the facilities. The health staff that had training in various community-based programs aimed at improving child survival was $93.3 \%$. These include CHPS, C-IMCI, CCM, CMAM, and NMCCS. Of those who had training $80.2 \%$ were trained in less than one year, $6.6 \%$ in less than six months, and another $6.6 \%$ in more than one year. $6.6 \%$ do not remember when they were trained. $53.3 \%$ of the staff interviewed also upgraded their knowledge through training workshops, $6.6 \%$ through searching the internet, $26.6 \%$ through reading, and $13.3 \%$ through research.

There was high acceptance that community members take part in management meetings and that communities have the village/community level health committees. $73.3 \%$ of the staff interviewed alluded to the fact that community members help in community mobilization for health, and all the staff interviewed said they accept suggestion from community members to improve their service. It was also found out that no facility has in place effective system for determining client opinion but indicated that all the facilities reported to participate in NHIS. It was also revealed that $40 \%$ of the facility had no printed referral forms.

All the CHOs interviewed said CBAs provided basic community case management for uncomplicated malaria, diarrhea, and ARI which reduced delays in seeking health and also reduced pressure and work load on the $\mathrm{CHO}$ at the facility level. There was also high in acceptance that the CBAs have adequate drugs to meet the community needs. The source of the drugs was from the district medical stores and UNICEF.

Community Integrated Management of Childhood Illnesses (C-IMCI), Community Case Management (CCM), Community Management of Acute Malnutrition (CMAM), Outreach services for Child Welfare Clinics, Expanded Programme on Immunization (EPI), Growth Promotion, Home Visit, Defaulter Tracing and Health Education were identified as the programs and interventions put in place to improve child survival. However, the most effective according to the interviewee was C-IMCI (60\%), Home visit $(20 \%)$ and growth monitoring.

\subsection{Discussion of results}

\subsection{Care giver knowledge on management and practice of childhood illness}

Improved child caregivers knowledge and practices may significantly reduce the incidence of diarrhea in children which will positively affect child survival. The study established very high knowledge of caregivers on prevention of diarrhea. The study took note of the following preventive measures; hand washing before feeding the child, washing children's hand with soap after toilet, cutting child's finger nail shot, practicing exclusive breastfeeding for children bellow six months, washing fruit or vegetables before child eats, using cups and spoons instead of bottle feeding, giving well cooked and warm food to child, keeping flies away from food, proper disposal of refuse, and the use of ORS to prevent diarrhea. These represent most of preventive measures outline by C-IMCI developed by $\mathrm{MOH}, \mathrm{WHO}$ and UNICEF (MOH, 2010).

There was over $90 \%$ acceptance to almost all the various statement that was put to assess caregivers' knowledge on prevention of diarrhea. The study found low level of knowledge for appropriate drug treatment recommended by $\mathrm{MOH}$ for diarrhea by caregivers. Majority $(52.5 \%)$ of the respondents used only ORS to treat diarrhea whiles $39.9 \%$ used ORS + zinc to treat diarrhea which is the recommended combination in recent time. Traditional treatment of diarrhea was not widespread practice (3\%). However, further study needs to be done to ascertain its usefulness. Knowledge of $\mathrm{MOH}$ recommended treatment for diarrhea was rather very high (93.9\%)among CBAs. This difference in knowledge might be because of the CIMCI training the CBAs had gone through. The hope is that knowledge would be translated to practice and then transferred to the child as the final beneficiaries. 
The study revealed that almost all the caregivers (99.2\%)knew that children with diarrhea need to be given more drink. About the same number knew that they do so to replace loss fluid. The caregivers had knowledge of Oral Rehydration Salt, for instance large proportion can correctly described preparation of ORS. Greater proportion accepted to give breast milk followed by ORS to baby less than six months with diarrhea. This is in line with the components of WHO diarrhea control program (correct knowledge and use of oral rehydration solution). This is also consistent with the studies by King (2010), and in contrast with study by McLennan (2000).The knowledge level does not reflect the reality on ground. The high episodes of diarrhea cases may be due to lack of Latrines in most household (91.5\%), coupled with one of the most common used source of water for the household (river and dam) for which majority of the household $(62.5 \%)$ does not do anything to the water to make it safer to drink. Therefore diarrhea control program needs to be reinforced to improve existing preventions and practices regarding management of acute diarrhea in children less five years of age.

Knowledge on prevention of malaria was also very high (over 90\%), they recognized the following as preventive measures for malaria; sleeping under insecticide treated bed, weeding the surrounding of homes to prevent breading of mosquitoes, draining stagnant water to prevent mosquitoes breeding, covering water containers to prevent breeding of mosquitoes, screening doors and windows to prevent mosquito bites. These are also the recommended measures outline by CIMCI developed by MOH, WHO and UNICEF (MOH, 2010).

The finding showed adequate knowledge of caregivers in preventing and managing children with convulsion, by bathing children with lukewarm water and give paracetamol to reduce temperature. Almost all the caregivers said they heard the term malaria and agreed strongly to the fact that people became infected with malaria from mosquito bite. Half of the caregivers indicated Artemisinin Combination Therapy (ACT)plus paracetamol, as the correct medicine to treat malaria, and could indicate the correct knowledge of dosages and right number of days ACT is given to a child with malaria even if the child gets better. ACT is $\mathrm{MOH}$ recommended first-line treatment of uncomplicated malaria, a recommendation of the World Health Organization (WHO, 2005).

Greater proportion of caregivers showed knowledge of pneumonia and were aware of at least one sign of pneumonia. Fever, cough, chest in-drawing, and fast breathing were highly associated with pneumonia. $85 \%$ were of the view that antibiotics are treatment for pneumonia. Even though the study showed knowledge of caregivers on recommended drug treatments for diarrhea, malaria and pneumonia, majority said last episodes of severe diarrhea, malaria, or pneumonia, were referred to health facility.

Comparison of knowledge and practice between communities that have health facility and communities that lack health facility revealed similarities in the respondents in terms of; giving more drink to child with diarrhea, the reasons for giving more drink, the number who know ORS, the number who can described ORS, the number said to give breast milk followed by ORS to a baby less than six months with diarrhea, the number heard about malaria, the agreement that people become infected with malaria from mosquito bite and the number who heard about pneumonia.

There was statistically significant difference beyond 5\% level in the use of drugs to treat diarrhea, number who can prepared ORS, management of child to prevent convulsion, correct medicine to treat malaria, number of days ACT is given to a child with malaria, knowledge of signs of pneumonia, and correct knowledge of dosage of ACT and paracetamol. The study revealed that there was high knowledge and practice among those with health facility than those without health facility. This difference may be due to exposure because of easy access and availability of health care services.

The study also revealed that most of the CBAs identified diarrhea by frequent passage of stools, watery stool for more than three times a day and with or without dehydration and sunken eyes. Majority of CBAs identified Pneumonia by fast breathing, others CBAs as child 
South American Journal of Public Health

Special Edition May 2016

with chest in-drawing, cough, and difficulty breathing. Malaria was also identified by rise in body temperature and weakness.

Knowledge was found to be high (93.9\%)in terms of drug treatment for diarrhea, ARI, and malaria. CBAs used ORS plus Zinc for diarrhea treatment, amoxicillin for ARI and ACT for malaria. The finding also showed adequate knowledge of CBAs in danger signs. Convulsion, blood in stools, child notable to eat or breastfeed, severe dehydration and when the condition is not improving after taking appropriate drugs for three days were the indications of signs of severe illness. Sick children were said to be referred to the next level when they present persistent any of the danger signs.

Majority of the CBAs assessed malnutrition by the used of MUAC tape and observation of weight loss. And if a child was assessed to be showing signs of malnutrition, the child was referred to appropriate health facility.

The CBAs involvement in C-IMCI could therefore be the most appropriate strategy for home and community level management of diarrhea, malaria and pneumonia. It also ensured prompt attention to reduced complications of illness. What is needed is to keep them upgraded through training.

\subsection{Health seeking behaviour of caregivers}

Results from the study found no factor preventing caregivers from seeking care, majority of the caregivers sought help from CBA and husbands if child is ill. This further brought to light the community confidence in the CBAs. Therefore the CBA concept, if giving the needed assistance and training can improve child survival. Notwithstanding the effort of the district health management to provide scientific and appropriate health care to all children some $1.8 \%$ still seeks help from traditional healer and $22.4 \%$ from chemical seller. This study was limited in finding the reasons for these behaviors. Further investigations are therefore needed in this direction to explore the reasons and it effects.

For medicine that are kept at home, the finds were that many household showed possession of ORS and paracetamol, and fewer household indicated presence of ACT, Chloroquine, Zinc, Amoxycillin and traditional medicine. This is an indication of household preparedness to provide their children first aid before seeking appropriate health care. However, the finding is worrisome as some household still have in their possession chloroquine which use is highly discourage by $\mathrm{MOH} / \mathrm{GHS}$. This finding has implication for education effort to increase appropriate treatment of malaria and established systems to maintain an adequate supply of $\mathrm{ACT}$ and reinforce partnership between CBAs and the communities they serve. This will contribute to eliminating the use of chloroquine.

It was also clear from the study that presence of danger signs (perceived severity) determines why families seek care for their sick children at the facility. This is consistent with health belief model. According to the Rosenstock model of health belief cited by Glanz, et al (2002), perceived severity (an individual's assessment of the seriousness of the condition, and its potential consequences) and perceived susceptibility (an individual's assessment of their risk of getting the condition)influence individual to seek for health. The finding further identified that only $13.1 \%$ and $31.8 \%$ will seek care as a result of proximity to health facility and perceived competence/quality of service rendered respectively. This again found to be consistent with the health belief model. That is perceived barriers (an individual's assessment of the influences that facilitate or discourage adoption of the promoted behavior) and perceived benefits (an individual's assessment of the positive consequences of adopting the behavior).

Chi-square $\left(X^{2}\right)$ analysis showed significant difference regarding keeping ORS, ACT, paracetamol, zinc and amoxicillin at household. It is noted from the finding also that there is statistically significant association between caregivers health seeking behavior and presence of health facility concerning person from whom help is sought if child is ill, where medicine is bought, where caregivers first seek care for sick children, reason why families seek care for their sick children at health facility, the distance from home or community to the nearest 
health facility and the means of transportation to facility. These suggest that availability of community-based primary health care may influence health seeking behavior.

Concerning distance and health seeking behavior, one-way ANOVA showed no significant difference among the means regarding person from whom help is sought if child is ill $\mathrm{F}(3)=$ $1.62 ; \mathrm{p}>0.01)$, but showed $\mathrm{F}$ to be significant beyond 0.01 level regarding where medicine is bought $(\mathrm{F}(3)=5.03 ; \mathrm{p}<0.01)$. The findings also showed significant difference regarding ORS, $\mathrm{ACT}$, chloroquine, zinc, Amoxycillin, and traditional medicine of the list of drugs that are kept at home by caregivers. However, there is a significant relationship beyond $1 \%$ level concerning where caregivers first seek care for sick children $(F(3)=8.4 ; p<0.01)$. There was no association among the means beyond $5 \%$ level regarding reason why families seek care for their sick children at health facility: $F(3)=2.64 ; p=0.050$ All these findings are helpful hints that community-based health care can be made practicably accessible and available in all the communities in the district. Therefore, there is the need to continuously upgrading the knowledge and skills of CHOs and CBAs to be able to implement comprehensive community based health care.

\subsection{Child morbidity and mortality}

The most common causes of morbidity and mortality for children during the first five years of life continue to be infections such as malaria, diarrhea and respiratory infections. From the result of the household survey, Fever (malaria) was found to be the most common illness suffered by the children of less than five years. Closely followed was diarrhea. ARI represents $11.8 \%$ and malnutrition $1.5 \%$. According to the CBAs diarrhea was the most common illness suffered by children followed by malaria then ARI. The CBAs also identified malaria to be the number one cause of death in under-fives, next by diarrhea, ARI and malnutrition. This conformed to the household survey findings. These disease conditions are the major public health problem in the developing countries including Ghana. Therefore, any intervention aimed at minimizing the occurrence of these conditions will go a long way to achieving the MDG for child survival.

Fever (malaria)once again was found to be responsible for a large proportion of childhood deaths. Malaria is rivaled in importance only by diarrhea and ARI (pneumonia)as causes of child mortality in the district. The review of the 33 CBAs registers revealed a total of 38 under- fives deaths within a year. According to the CBAs registers malaria again was found to be the major cause of deaths in under-fives followed by diarrhea and ARI (pneumonia). This finding conformed to several findings by world researchers (Abhay et al, 2012; Seyal, \& Hanifa, 2009; and Rutherford et al, 2009) and consistent with report of the Yendi Municipal Health Management Team, (YMHMT, 2010), and findings by WHO Regional office for Africa (WHO, 2010).

A cross-tabulation of presence of health facility and number of child death within the last five years showed higher percentage $(12.9 \%)$ of death in communities without heath facility and lower percentage $(7.6 \%)$ of deaths in communities with health facility. The study suggest that poor access to health care, which results in delayed attendance at health facility or none at all, may be a determinant to child survival. This is an indication that improved community based health service could contribute significantly to increasing child survival.

\subsection{Community participation in child survival interventions}

The study identified a greater community mobilization and participation in child health services. The community resources such as TBAs, mother-to-mother support groups and CBAs were utilized in the mobilization of child health programs. The CHOs agreed community members taking part in management meetings and that communities have the village/community level health committees. $73.3 \%$ of the CHOs interviewed alluded to the fact that community members help in community mobilization for health, and all the staff interviewed said they accept suggestion from community members to improve their service. This indicates social cohesion in the community between community members and 
South American Journal of Public Health

Special Edition May 2016

community health officers. However, the study also found out that no facility has in place effective system for determining client opinion.

\subsection{Conclusion}

The study met its objectives by looking at all the research questions. However, some issues were overlooked at the early stage of the design of the study and therefore were not addressed. Some of such issues are the reasons for seeking traditional/herbal medicine for children and how to address immunization failure. Therefore, future study could look at the issue of this relevant health seeking behavior.

The general conclusions were that there was general improvement in the health and survival of children less than five years of age. This was however, better in communities with health facility. Hence community-based primary health care have a positive effects on child survival.

\section{References}

[1.] Abhay, B.M., Dohare, S., AND Gitte, S.V., (2012). Child health: Understanding the home care practices in some illnesses among Under-five children in IMNCI implemented rural area. International Journal of Biological \& Medical Research, 3(5): 1251-1254

[2.] Ahmad, O.B., Lopez, A.D., Inoue, M. (2000). The decline in child mortality: Reapraisal Bulletin WHO 78: 1175-1191

[3.] American Public Health Association (2009). Report to the Expert Review Panel, CommunityBased Primary Health Care Working Group, International Health Section, American Public Health Association. Retrieved on 25/11/2011 from http://www.apha.org/membergroups/sections/aphasections/intlhealth/cbphcw

[4.] Anaman, K.A. (2003). Research Methods in Applied Economics and Other Social Sciences. Bandar Seri Begawan: Brunei Press, Sendirian Berhad

[5.] Black R. E., Morris S. S., Bryce J. (2003). Where and why are 10 million children dying every year? The lancent, 361:2226-34.

[6.] Breman J.G, Egan A, Keusch G. T. (2001). The intolerable burden of malaria: a new look at the numbers. American Journal of Tropical Medicine Hygiene. 64 (Suppl 1):iv-vii.

[7.] Bryc EJ, Arifeen S., Pariyo G., Lanata C., Gwatkin D, Habicht J.P. (2003). Reducing child mortality: Can public health deliver? The Lancet; 362:159-64.

[8.] Cooper, D. R. \& Schindler, P. S. (2001). Business Research Methods, New York: McGraw-Hill Company

[9.] Daily GraphiC(2012). Reducing child mortality by 2015 is off track. Daily Graphic, Wednesday, November 21, 2012.

[10.] Darmstadt, G. L., Bhutta, Z. A., Cousens, S., Adam, T., Walker, N. \& De Bernis, L. (2005). Evidence-based, cost-effective interventions: How many newborn babies can we save? Lancet, 365, $977-988$

[11.] Easterby-Smith, M., Thorpe, R. \& Lowe, A. (2002). Management Research: An Introduction (2nd ed), London: Sage publications

[12.] Ghana Statistical Service \& Ghana Health Service (2008). Ghana Demographic and Health Survey, Accra: Ghana ICF Macro Calverton, Maryland, U.S.A.

[13.] Ghana Statistical Service \& Ghana Health Service, (2009). Ghana Maternal Health Survey. Calverton Maryland: GSS, GHS, and Macro International, Inc.

[14.] Glanz K, Lewis FM, Rimer BK. (2002). "Health Behavior and Health Education" ISBN 0787957151

[15.] Jones, G., Steketee, R. W., Black, R. E., Bhutta, Z. A. \& Morris, S. S. (2003). How many child deaths can we prevent this year? Lancet, 362, 65-71.

[16.] King, R., Mann, V., \& Boone, P. D., (2010). Knowledge and reported practice of men and women on metal and child health in rural Guinea Bissau: a cross sectional survey. Bio Med Central public health publication; 1471- 2458/10: 319 
[17.] Kumekpor, T. K. B. (2002). Research methods and Techniques of social Research. Accra: Son Life Press and Services: $\mathrm{p} 132$

[18.] Mclennan, J. D. (2000). Prevention of Diarrhoea in a Poor District of Santo Domingo, Dominican Republic: Practices, Knowledge, and Barriers. Center for health and Population Research, Journal of Health and Nutrition, 18(1):15-22

[19.] MOH \& GHS, (2010). Home management of malaria, Acute Respiratory Infection, and Diarrhea in Ghana: Participants’ Training Manual, Accra: NMCP, GHS

[21.] Perry, H. \& Freeman, P. (2009). A Review of the Evidence: How Effective Is Community-Based Primary Health Care in Improving the Health of Children? Summary Findings

[22.] Perry, H., Berggren, W., Berggren, G., Dowell, D., Menager, H., Bottex, E., Dortonne, J. R., Philippe, F. \& Cayemittes, M. (2007a). Long-term reductions in mortality among children under age 5 in rural Haiti: effects of a comprehensive health system in an impoverished setting. American Journal of Public Health, 97, 240-6.

[23.] Perry, H., Freeman, P., Rassekh, B. \& Gupta, S. (2009a). How cost-effective is community-based primary health care in improving child health? World Health Organ, 84, 949-

[24.] Perry, H., Northrup, R., Bryant, J., Berggren, W. \& Berggren, G., (2009b). The cost-effectiveness of a long-term comprehensive primary health care program in reducing under-5 mortality: findings from rural Haiti. Document submitted for publication

[25.] Phillips, J. F., Bawah, A. A. \& Binka, F. N. (2006), Accelerating reproductive and child health program, impact with community-based services: the Navrongo experiment in Ghana. Bulletin of the world health organization; 84, 949-55.

[26.] Rutherford E. M., Dockertyy, J. D, Jasseh, M., Howie, S.R.C., Herbison, P., Jeffries, D.J. Leach, M., Stevens, W, Mulholland, K, Adegbola R.A., Hill, P. C, (2009). Access to health care and mortality of children under 5 years of age in the Gambia: a case-control study. Bulletin of WHO; 87:216-224.

[27.] Saunders, M., Lewis, P \& Thornhill, A., (2007). Research Methods for Business Students (4th edn)Harlow: Pearson Education Limited.

[28.] Schellenberg JA, Victora CG, Mushi A, De Savigny D, Schellenberg D, Mshinda H, Bryce J. (2003). Tanzania Integrated Management of Childhood Illness MCE Baseline Household Survey Study Group. Inequities among the very poor: health care for children in rural southern Tanzania. Lancet.; 361:561-6

[29.] Seyal, T. \& Hanif, A. (2009). Knowledge, Attitude and Practices of the Mothers and Doctors Regarding Feeding, Oral Rehydration Solution (ORS)and Use of Drugs in Children during Acute Diarrhea. ANNALS, vol 15. No. 1: 38-41

[30.] UNICEF (2008a). State of the World's Children 2008, New York, NY: United Nations Children's Fund. Oxford University Press

[31.] UNITED NATIONS (2000). Resolution 55/2 adopted by the General Assembly: United Nations Millennium Declaration

[32.] Varkevisser C. M., Pathmanathan I. \&, Brownlee A. (2003). Designing and Conducting Health Systems Reseach Projects: Health System Research Training Serirs. Vol II part 1, Ottawa: IDRCand WHO.

[33.] WHO \& UNICEF (1978). Alma Ata Declaration, USSR, December 6-12, 1978. Geneva, Switzerland: World Health Organization. Primary Health Care, Report on the International Conference on Primary Health Care.

[34.] WHO (2006). Multicenter Growth Reference Study Group, WHO child growth standards: Length/height-for-age, weight-for-age, weight-for-length, weight-for-height and body mass index-forage: Methods and development. Geneva: World Health Organization

[35.] WHO Regional office for Africa, (2010). Ghana Factsheets of Health Statistics 2010. Retrieved from: ghndp.org/childmedicines or http://childmedicines.ghndp.org 13:32

[36.] WHO, (2005). The World health report: make every mother and child count. Geneva, Switzerland: World Health Organization.

[37.] Yendi District Health MANagement Team (2010). Annual performance review, Yendi Municipal Health Directorate 
South American Journal of Public Health

Special Edition May 2016

[38.] Yendi District Health Management Team (2011). Annual performance review: 2011 programme of work, Yendi: Municipal Health Directorate 43

Table 1.0: Socio Demographics Characteristics of Respondent

\begin{tabular}{|ll|}
\hline Variable & percentage \\
\hline Sex of household head & \\
Male & 95.8 \\
Female & 4.2 \\
\hline Age of woman in years & \\
14-19 & 2.6 \\
$20-25$ & 33.8 \\
$26-30$ & 36.1 \\
$31-35$ & 15.9 \\
36-40 & 11.0 \\
Don't know & 0.8 \\
\hline Marital status of woman & \\
Single & 2.5 \\
Married & 96.2 \\
Separated & 0.5 \\
Divorced & 0.8 \\
\hline Ethnic grouping of household & \\
Mole Dagbonba & 54.0 \\
Konkomba & 44.8 \\
Gonja & 0.2 \\
Other (specify) & 1.0 \\
\hline Religion practiced by the household & \\
Muslim & 63.9 \\
Christian & 14.3 \\
Traditional & 18.3 \\
No religion & 3.5 \\
Other & 1.0 \\
\hline Level of education attained by mother & \\
No education & 85.5 \\
Primary & 9.3 \\
Midle/JSS/JHS & 4.1 \\
SSS/SHS/Tec/Voc & 0.8 \\
Tertiary & 0.3 \\
\hline Souce:prinary data. Totals may not sum up to & \\
\hline
\end{tabular}

Source: primary data. Totals may not sum up to $n=400$ due to missing observations

Table 2: Knowledge on Diarrhea and Malaria Prevention of the respondents

\begin{tabular}{|c|c|c|c|c|c|}
\hline Variable & $\begin{array}{l}\text { Strongly } \\
\text { Agree }(\%)\end{array}$ & $\begin{array}{l}\text { Agree } \\
(\%)\end{array}$ & $\begin{array}{l}\text { Disagree } \\
(\%)\end{array}$ & $\begin{array}{l}\text { Strongly } \\
\text { Disagree } \\
(\%)\end{array}$ & $\begin{array}{l}\text { Total } \\
(\%)\end{array}$ \\
\hline $\begin{array}{l}\text { Wash hands before feeding the } \\
\text { child or wash child's hands before } \\
\text { he/she eats }\end{array}$ & 62.3 & 36.2 & 1.3 & 0.3 & 100 \\
\hline $\begin{array}{l}\text { Wash child's hands with soap after } \\
\text { toilet }\end{array}$ & 54.8 & 37.2 & 7.5 & 0.5 & 100 \\
\hline $\begin{array}{l}\text { Practice exclusive breastfeeding } \\
\text { for children below } 6 \text { months }\end{array}$ & 44.9 & 41.9 & 1.3 & 0.2 & 100 \\
\hline Cut child's finger nails shot & 54.5 & 41.0 & 4.2 & 0.3 & 100 \\
\hline $\begin{array}{l}\text { Wash fruits or vegetables } \\
\text { thoroughly before the child eats }\end{array}$ & 54.4 & 44.1 & 0.0 & 1.5 & 100 \\
\hline
\end{tabular}




\begin{tabular}{|c|c|c|c|c|c|}
\hline them & & & & & \\
\hline $\begin{array}{l}\text { Do not use feeding bottles, instead } \\
\text { use cups, plates and spoons }\end{array}$ & 49.9 & 41.9 & 1.3 & 0.2 & 100 \\
\hline Give the child clean water & 59.3 & 38.4 & 2.0 & 0.3 & 100 \\
\hline Give the child well cooked food & 61.2 & 37.0 & 0.0 & 1.8 & 100 \\
\hline $\begin{array}{l}\text { Heat food when cold before given } \\
\text { to child }\end{array}$ & 56.7 & 39.5 & 3.3 & 0.5 & 100 \\
\hline $\begin{array}{l}\text { Cover prepare food to keep flies } \\
\text { away }\end{array}$ & 59.4 & 38.6 & 0.0 & 2.0 & 100 \\
\hline $\begin{array}{l}\text { Cover all dustbins and properly } \\
\text { dispose of all refuse in a pit }\end{array}$ & 48.7 & 34.4 & 15.6 & 1.3 & 100 \\
\hline $\begin{array}{l}\text { Train children to use the chamber } \\
\text { pot as early as possible and dispose } \\
\text { of the waste immediately and } \\
\text { properly }\end{array}$ & 51.9 & 32.2 & 12.9 & 3.0 & 100 \\
\hline $\begin{array}{l}\text { Let child sleep under an } \\
\text { insecticide-Treated bed net }\end{array}$ & 62.4 & 31.8 & 5.5 & 0.3 & 100 \\
\hline $\begin{array}{l}\text { Weeding the surrounding of homes } \\
\text { to prevent the breeding of } \\
\text { mosquitoes }\end{array}$ & 63.4 & 34.3 & 0.0 & 2.3 & 100 \\
\hline $\begin{array}{l}\text { Draining stagnant/pool of water to } \\
\text { prevent the breeding of mosquitoes }\end{array}$ & 57.8 & 34.7 & 7.3 & 0.2 & 100 \\
\hline $\begin{array}{l}\text { Covering water containers in the } \\
\text { house always to prevent the } \\
\text { breeding of mosquitoes }\end{array}$ & 54.9 & 42.1 & 2.8 & 0.2 & 100 \\
\hline
\end{tabular}

Table 3.0: Household management of child illness of the respondents

Knowledge and practice of care givers Comparison between Communities that have Health Facility and Communities without Health Facility

\begin{tabular}{|c|c|c|c|c|}
\hline Variables & $\begin{array}{l}\text { Percentage } \\
(\%)\end{array}$ & $\begin{array}{l}\text { Community } \\
\text { with health } \\
\text { facility }(\%)\end{array}$ & $\begin{array}{l}\text { Community } \\
\text { without health } \\
\text { facility }(\%)\end{array}$ & $\mathrm{P}$ values \\
\hline \multicolumn{5}{|l|}{ Drugs used to treat diarrhea } \\
\hline ORS & 52.5 & 62.9 & 44.3 & \multirow{7}{*}{0.001} \\
\hline Zinc Tablets & 1.8 & 1.7 & 1.8 & \\
\hline ORS + Zinc tablets & 39.9 & 32 & 46.1 & \\
\hline Other & 0.8 & 1.7 & 0.0 & \\
\hline Traditional & 3.0 & 1.1 & 4.6 & \\
\hline Other over counter drugs & 0.5 & 0.6 & 0.5 & \\
\hline Do nothing & 1.5 & 0.0 & 2.7 & \\
\hline $\begin{array}{l}\text { Number who give more drink to } \\
\text { child with diarrhea }\end{array}$ & 90.2 & 93.8 & 87.2 & 0.280 \\
\hline $\begin{array}{l}\text { Number who know why more } \\
\text { drink is given }\end{array}$ & 70.7 & 66.9 & 33.1 & 0.159 \\
\hline Number who know ORS & 99.2 & 99.4 & 99.1 & 0.699 \\
\hline $\begin{array}{l}\text { Number who can describe ORS } \\
\text { Correctly }\end{array}$ & 91.3 & 92.5 & 90.3 & 0.433 \\
\hline $\begin{array}{l}\text { Number said to give breast milk } \\
\text { followed by ORS to a baby } \\
\text { under } 6 \text { months with diarrhea }\end{array}$ & 78.1 & 76.0 & 24.0 & 0.383 \\
\hline
\end{tabular}


South American Journal of Public Health

Special Edition May 2016

\begin{tabular}{|c|c|c|c|c|}
\hline $\begin{array}{l}\text { Number who can describe } \\
\text { preparation of ORS Correctly }\end{array}$ & 72.8 & 80.3 & 66.7 & 0.010 \\
\hline \multicolumn{5}{|l|}{$\begin{array}{l}\text { Management of child to prevent } \\
\text { convulsion }\end{array}$} \\
\hline $\begin{array}{l}\text { Dress child lightly and cool with } \\
\text { damp cloth if child is sick with } \\
\text { fever }\end{array}$ & 6.6 & 9.7 & 4.1 & \multirow{3}{*}{0.000} \\
\hline $\begin{array}{l}\text { Bath child with lukewarm water } \\
\text { to reduce temperature }\end{array}$ & 39.1 & 54.3 & 27.3 & \\
\hline $\begin{array}{l}\text { Bath child with lukewarm water } \\
\text { and give paracetamol to reduce } \\
\text { temperature }\end{array}$ & 51.5 & 34.9 & 64.5 & \\
\hline Number heard about malaria & 95 & 94.4 & 94.5 & 0.564 \\
\hline \multicolumn{5}{|l|}{ correct medicines to treat malaria } \\
\hline Chloroquine & 2.6 & 3.6 & 1.8 & \multirow{7}{*}{0.005} \\
\hline Paracetamol & 2.8 & 3.6 & 2.3 & \\
\hline Chloroquine + Paracetamol & 13.1 & 19.6 & 7.8 & \\
\hline Fancider & 0.8 & 0.6 & 0.9 & \\
\hline ACT & 23.2 & 23.8 & 22.8 & \\
\hline ACT + paracetamol & 56.4 & 47.0 & 63.9 & \\
\hline Other & 1.0 & 1.8 & 0.5 & \\
\hline \multicolumn{5}{|l|}{$\begin{array}{l}\text { Number of day(s)ACT is given to } \\
\text { a child with malaria even if the } \\
\text { child gets better }\end{array}$} \\
\hline 1 day & 4.4 & 4.2 & 4.6 & \multirow{4}{*}{0.001} \\
\hline at least for 2 days & 3.9 & 3.0 & 4.6 & \\
\hline at least for 3 days & 86.1 & 92.3 & 81.1 & \\
\hline at least for 7 days & 5.7 & 0.6 & 9.6 & \\
\hline Number heard about pneumonia & 92.0 & 92.5 & 91.7 & 0.782 \\
\hline \multicolumn{5}{|c|}{ Recognition of signs of pneumonia } \\
\hline fever & 83.4 & 95.0 & 74.8 & \multirow{4}{*}{0.000} \\
\hline chest in-drawing & 78.9 & 92.9 & 67.6 & \\
\hline fast breathing & 79.1 & 88.8 & 71.6 & \\
\hline Cough & 89.5 & 95.1 & 85.4 & \\
\hline \multicolumn{5}{|l|}{$\begin{array}{l}\text { Antibiotics are treatment for } \\
\text { pneumonia }\end{array}$} \\
\hline Strongly agree & 43.9 & 46.4 & 41.7 & \multirow{4}{*}{0.101} \\
\hline Agree & 41.0 & 42.9 & 39.8 & \\
\hline Disagree & 12.7 & 10.1 & 14.8 & \\
\hline Strongly disagree & 2.3 & 0.6 & 3.7 & \\
\hline $\begin{array}{l}\text { Number said last episodes of } \\
\text { diarrhea, malaria or pneumonia } \\
\text { referred to health facilities }\end{array}$ & 68.1 & 55.6 & 78.1 & 0.000 \\
\hline \multicolumn{5}{|l|}{ Correct knowledge of dosage of: } \\
\hline $\mathrm{ACT}$ & 66.2 & 56.2 & 74.0 & \multirow[t]{2}{*}{0.000} \\
\hline Paracetamol & 78.2 & 68.3 & 85.6 & \\
\hline
\end{tabular}

Source: field survey 2014. Totals may not sum up to $n=400$ due to missing observations

Table 4.0: Health Seeking Behaviour of Respondent

\begin{tabular}{|l|l|l|l|l|}
\hline Variables & $\begin{array}{l}\text { Percentage } \\
(\%)\end{array}$ & $\begin{array}{l}\text { Presence of } \\
\text { heath facility }\end{array}$ & Chi-Square $\left(\chi^{2}\right)$ \\
\hline Person from whom help is sought if child & & Yes & No & \\
\hline
\end{tabular}


South American Journal of Public Health

Special Edition May 2016

\begin{tabular}{|c|c|c|c|c|}
\hline is ill & & & & \\
\hline Another Parent & 1.8 & \multirow{8}{*}{179} & \multirow{8}{*}{219} & \multirow{8}{*}{$\begin{array}{c}\chi^{2}=16.02 ; \\
\mathrm{df}=6 ; \mathrm{p}=0.014\end{array}$} \\
\hline Mother in-law & 7.8 & & & \\
\hline Relative & 3.3 & & & \\
\hline Friends & 0.0 & & & \\
\hline Traditional Healer & 1.8 & & & \\
\hline Other & 0.3 & & & \\
\hline CBA & 53.6 & & & \\
\hline Husband & 31.6 & & & \\
\hline \multicolumn{5}{|l|}{ Where is medicine bought normally } \\
\hline Local Person & 12.1 & \multirow{6}{*}{179} & \multirow{6}{*}{208} & \multirow{6}{*}{$\begin{array}{c}\chi^{2}=73.31 ; \\
\mathrm{df}=5 ; \mathrm{p}=0.00\end{array}$} \\
\hline Chemical seller & 22.4 & & & \\
\hline Relative & 0.3 & & & \\
\hline CBA & 51.8 & & & \\
\hline Local clinic & 12.9 & & & \\
\hline Other & 0.5 & & & \\
\hline \multicolumn{5}{|l|}{ Presence of ORS in the household } \\
\hline Yes & 71.0 & \multirow{2}{*}{169} & \multirow{2}{*}{219} & \multirow{2}{*}{$\begin{array}{c}\chi^{2}=19.87 \\
\mathrm{df}=1 ; \mathrm{p}=0.00\end{array}$} \\
\hline No & 29.0 & & & \\
\hline \multicolumn{5}{|l|}{ Presence of ACT in the household } \\
\hline Yes & 46.9 & \multirow{2}{*}{173} & \multirow[b]{2}{*}{218} & \multirow{2}{*}{$\begin{array}{c}\chi 2=56.91 \\
\mathrm{df}=1 ; \mathrm{p}=0.00\end{array}$} \\
\hline No & 53.1 & & & \\
\hline \multicolumn{5}{|l|}{ Presence of Chloroquine in the household } \\
\hline Yes & 22.5 & \multirow{2}{*}{196} & \multirow{2}{*}{206} & \multirow{2}{*}{$\begin{array}{c}\chi^{2}=0.073 \\
\mathrm{df}=1 ; \mathrm{p}=0.79\end{array}$} \\
\hline No & 71.5 & & & \\
\hline \multicolumn{5}{|l|}{ Presence of Paracetamol in the household } \\
\hline Yes & 75.3 & \multirow{2}{*}{160} & \multirow{2}{*}{207} & \multirow{2}{*}{$\begin{array}{c}\chi^{2}=16.296 \\
\mathrm{df}=1 ; p=0.00\end{array}$} \\
\hline No & 24.7 & & & \\
\hline Presence of Zinc tab in the household & & & & \\
\hline Yes & 32.2 & & & $\chi^{2}=8.89$ \\
\hline No & 67.8 & $16 /$ & 214 & $\mathrm{df}=1 ; \mathrm{p}=0.003$ \\
\hline Presence of Amoxycilin in the household & & & & \\
\hline Yes & 37.7 & & & $\chi^{2}=13.495$ \\
\hline No & 62.3 & 163 & 218 & $\mathrm{df}=1 ; \mathrm{p}=0.00$ \\
\hline $\begin{array}{l}\text { Presence of Traditional Medicine in the } \\
\text { household }\end{array}$ & & & & \\
\hline Yes & 39.0 & & & $\chi^{2}=1.007$ \\
\hline No & 61.0 & 145 & 199 & $\mathrm{df}=1 ; \mathrm{p}=0.32$ \\
\hline $\begin{array}{l}\text { Place where care is usually first seek for } \\
\text { the sick child }\end{array}$ & & & & \\
\hline CBA & 54.4 & & & \\
\hline Clinic & 37.2 & & & $\chi^{2}=52.19$ \\
\hline Hospital & 2.3 & 171 & 217 & $\mathrm{df}=3 ; \mathrm{p}=0.00$ \\
\hline Chemical seller & 6.1 & & & \\
\hline $\begin{array}{l}\text { What determines why families seek care } \\
\text { for their sick children at facility }\end{array}$ & & & & \\
\hline Presence of danger signs eg. & 55.1 & & & \\
\hline Convulsion, & 13.1 & 165 & 215 & $\begin{array}{c}\chi=10.868 \\
f(=) \cdot n=0004\end{array}$ \\
\hline Proximity to health facility & 31.8 & & & $\mathrm{df}=2 ; \mathrm{p}=0.004$ \\
\hline $\begin{array}{l}\text { Perceived competence/quality of service } \\
\text { rendered }\end{array}$ & & & & \\
\hline
\end{tabular}


South American Journal of Public Health

Special Edition May 2016

\begin{tabular}{|c|c|c|c|c|}
\hline $\begin{array}{l}\text { Time taken to go from your home or } \\
\text { community to the nearest health facility }\end{array}$ & & & & \\
\hline Less than $30 \mathrm{~min}$ & 50.6 & \multirow{4}{*}{145} & \multirow{4}{*}{183} & \multirow{4}{*}{$\begin{array}{c}\chi^{2}=1.29 ; \mathrm{df}=3 \\
p=0.00\end{array}$} \\
\hline About 1 hour & 28.0 & & & \\
\hline More than 1 hours & 7.0 & & & \\
\hline More than 2 hours & 14.3 & & & \\
\hline $\begin{array}{l}\text { Means of Transport to nearest health } \\
\text { facility }\end{array}$ & & & & \\
\hline By foot & 57.8 & \multirow{3}{*}{179} & \multirow{3}{*}{218} & \multirow{3}{*}{$\begin{array}{c}\chi^{2}=16.18 \\
\mathrm{df}=2 ; \mathrm{p}=0.00\end{array}$} \\
\hline Bicycle & 36.2 & & & \\
\hline Motorbike & 6.0 & & & \\
\hline
\end{tabular}

Table 5.0: Association between Distance to Health Facility and Health Seeking Behaviour of the

\begin{tabular}{|l|l|l|l|l|l|}
\hline Health behavior & $\mathrm{SM}^{2}$ & $\mathrm{Df}$ & $\mathrm{M}^{2}$ & $\mathrm{~F}$ & sig \\
\hline Person from whom help is sought if child is ill & 13.54 & 3 & 4.51 & 1.62 & 0.186 \\
\hline Where is medicine bought normally & 24.15 & 3 & 8.05 & 5.03 & 0.002 \\
\hline ORS is kept at home & 3.20 & 3 & 1.07 & 4.88 & 0.002 \\
\hline ACT is kept at home & 10.81 & 3 & 3.60 & 17.87 & 0.000 \\
\hline Chloroquine is kept at home & 1.24 & 3 & 0.41 & 3.24 & 0.022 \\
\hline Paracetamol is kept at home & 0.70 & 3 & 0.24 & 1.26 & 0.289 \\
\hline Zir c tab is kept at home & 8.14 & 3 & 2.71 & 18.88 & 0.000 \\
\hline Amoxycilin is kept at home & 4.73 & 3 & 1.57 & 8.50 & 0.000 \\
\hline Traditional Medicine is kept at home & 2.76 & 3 & 0.32 & 1.72 & 0.180 \\
\hline Other medicine is kept at home & 0.96 & 3 & 0.32 & 1.72 & 0.180 \\
\hline Where do you usually first seek care for your sick child? & 16.08 & 3 & 5.36 & 8.42 & 0.000 \\
\hline $\begin{array}{l}\text { What determines why families seek care for their sick } \\
\text { children at facility }\end{array}$ & 6.45 & 3 & 2.15 & 2.64 & 0.050 \\
\hline Source: Field survey. Totals may not sum up to $n=400$ due to missing observations \\
\hline
\end{tabular}

Table 6.0: Cross-tabulation between Presences of Health Facility and Child Deaths

\begin{tabular}{|l|l|l|l|}
\hline & \multicolumn{4}{|c|}{ Have you lost any child within last 5 years } \\
\hline & & Yes & No \\
\hline Presence of health facility & Yes & 7.6 & 92.4 \\
\cline { 2 - 4 } & No & 12.9 & 87.1 \\
\hline Source: Field survey. Totals may not sum up to $f=400$ due missing observations \\
\hline
\end{tabular}

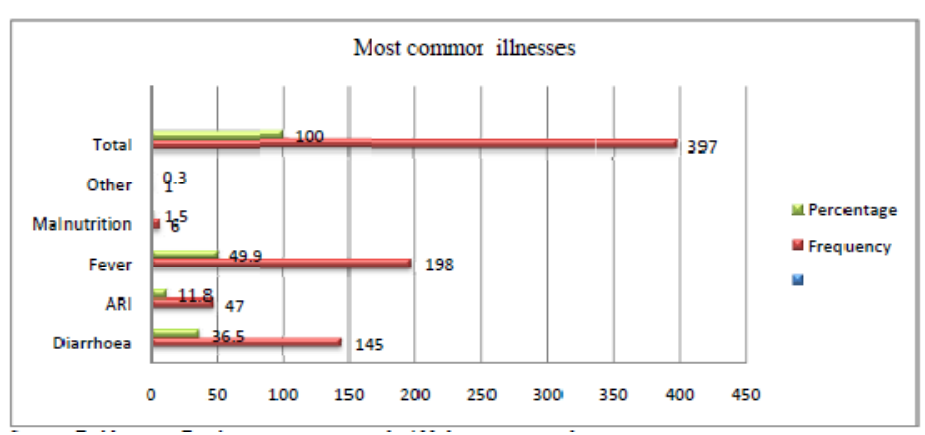

Figure 1: Common illnesses of children

Source: Field survey. Totals may not sum up to $f=400$ due missing observations 


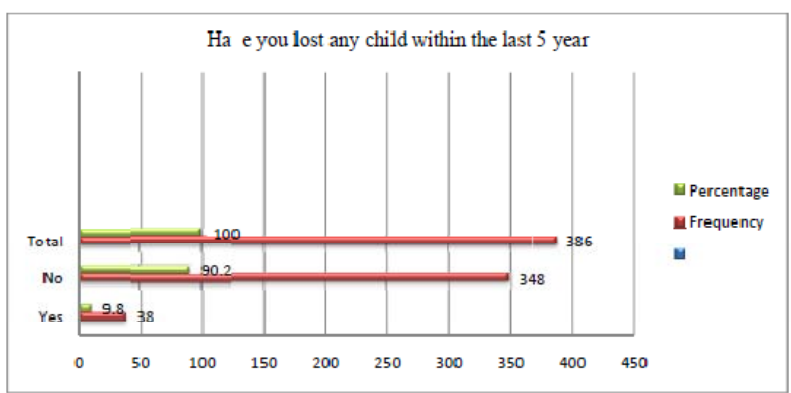

Figure 2: Child lost within last five years by caregivers

Source: Field survey. Totals may not sum up to $f=400$ due missing observations

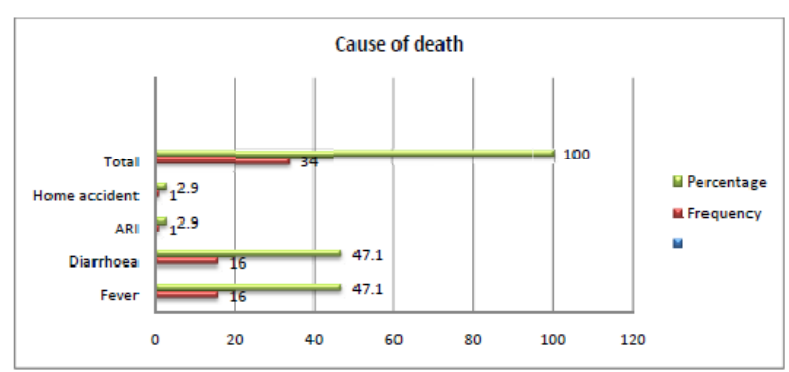

Figure 3: Causes of death of children

Source: Field survey. Totals may not sum up to $f=400$ due missing observations

\section{YENDI MUNICIPAL MAPSHOWING SUB-MUNICIPALS}

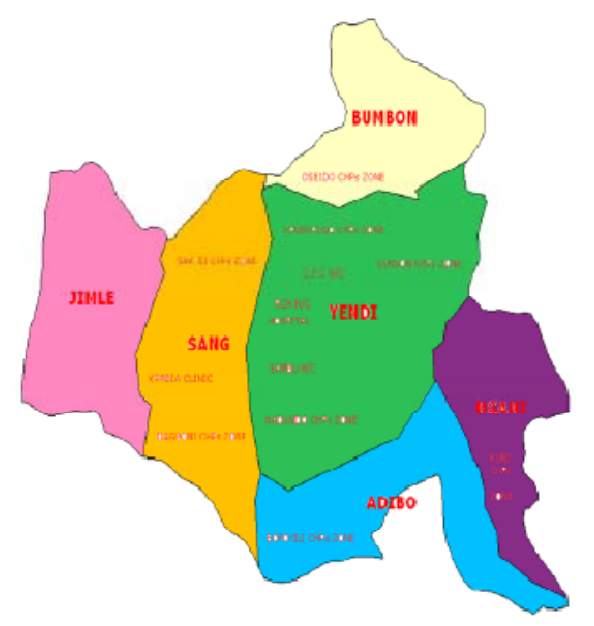

Appendix 1: Map showing the Research Area. 